\title{
MUTU KARAGINAN DAN KEKUATAAN GEL DARI RUMPUT LAUT MERAH Kappaphycus alvarezii
}

\author{
Sopina Erjanan ${ }^{1}$, Verly Dotulong ${ }^{2}$ dan Roike Montolalu ${ }^{2}$ \\ ${ }^{1)}$ Mahasiswa pada Program Studi Teknologi Hasil Perikanan FPIK Unsrat Manado \\ ${ }^{2)}$ Staf pengajar pada Program Studi Teknologi Hasil Perikanan FPIK Unsrat Manado \\ Email : erjanansopina@yahoo.com
}

\begin{abstract}
The study aim to determine the quality and gel strength of carrageenan produced by red algae Kappaphycus alvarezii. The carrageenan was produced using various concentration, cooking time and water ratio that is $0.05,0.1$ and $0.15 \%$ potassium hydroxide; $1,1.15,1.25,1.5,3$ and $4.5 \%$, potassium chloride $(\mathrm{KCl})$; cooking time $2 \mathrm{~h}$ or $3 \mathrm{~h}$; and carrageenan and water ratio, 1:20L or 1:30L The re sults showed that the best treatment produced the highest gel strength $\left(188.53 \mathrm{~g} / \mathrm{cm}^{2}\right)$ with $17.7 \%$ moisture content and $19.9 \%$ ash content. This condition was achived by mixing $0.15 \% \mathrm{KOH}$ and $1.25 \% \mathrm{KCl}$, cooked for $2 \mathrm{~h}$ with 1:20 carrageenan to water ratio.
\end{abstract}

Keyword: Carageenan, Kappaphycus alvarezii, seaweed.

Tujuan dari penelitian ini adalah untuk menentukan mutu akhir karaginan dari rumput laut merah Kappaphycus alvarezii yang dibuat dengan 5 perlakuan berbeda. Perlakuan variasi konsentrasi pelarut $\mathrm{KOH}$ dan $\mathrm{KCl}$, lama pemasakan, dan perbandingan air yang berbeda. Proses ekstraksi karaginan menggunakan pelarut $\mathrm{KOH}$ dengan konsentrasi $0,05 \%, 0,1 \%$, dan $0,15 \%$ sedangkan pelarut $\mathrm{KCl}$ dengan konsentrasi $1 \%, 1,15 \%, 1,25 \%, 1,5 \%, 3 \%$, dan 4,5\%, lama pemasakan 2 dan 3 jam, dan perbandingan air 1:20 L dan 1:30 L. Hasil penelitian menunjukkan bahwa perlakuan $\mathrm{F}$ dengan konsentrasi $\mathrm{KOH} 0,15+$ $\mathrm{KCl} 1,25 \%$ dan lama pemasakan 2 jam, dan perbandingan karaginan dan air 1:20 Liter menghasilkan kekuatan gel 188,53 g/cm², dengan pH 8,04, kadar air 17,75, dan kadar abu 19,99\%.

Kata Kunci: Karaginan, Kappaphycus alvarezii, rumput laut.

\section{PENDAHULUAN}

Rumput laut atau alga laut (seaweed) menempati posisi penting dalam produksi perikanan Indonesia, khususnya pada usaha perikanan non ikan. Rumput laut menjadi komoditas unggulan dalam sektor perikanan karena jumlah permintaannya yang terus meningkat, baik untuk kebutuhan domestik maupun untuk ekspor. Kebutuhan rumput laut diperkirakan terus meningkat seiring dengan meningkatnya kebutuhan konsumsi langsung maupun industri makanan, farmasi, dan kosmetik (Kordi, 2010, dalam Harun $d k k$, 2013).

Rumput laut Kappaphycus alvarezii merupakan komoditas unggulan penghasil karaginan yang banyak dimanfaatkan dalam industri kertas, tekstil, fotografi, pengalengan ikan dan pasta. Produksi karaginan Indonesia mencapai $80 \%$ (3.896 ton) dan yang diekspor adalah sebanyak 3.156 ton dalam tahun 2002 . Sedangkan di tahun 1996-2004, produksi dan ekspor karaginan Indonesia relatif konstan, dengan pertumbuhan masing-masing yaitu 2,92\% dan 2,49\% per tahun (Emma $d k k .2010$ ).

Rumput laut dapat digunakan sebagai bahan makanan, minuman dan obat-obatan beberapa hasil olahan seperti agar-agar, alginat, dan karaginan cukup penting dalam industri (Istini dan Suhaimi, 1998). Karaginan dipakai sebagai stabilisator, pengental, pembentuk gel, pengemulsi, pengikat dan pencegah kristalisasi dalam industri makanan ataupun minuman, farmasi dan kosmetik lainnya. Rumput laut diketahui kaya akan komponen seperti enzim, asam nukleat, asam amino, mineral, dan vitamin A, B, C, D, E dan K. Sebagian besar rumput laut di Indonesia diekspor dalam bentuk kering (Suwandi, 1992).

\section{METODOLOGI PENELITIAN}

Bahan utama yang digunakan untuk ekstraksi karaginan adalah rumput laut kering jenis Kappaphycus alvarezii, KOH (Kalium Hidroksida), $\mathrm{KCl}$ (Kalium Klorida) dan aquades. Alat-alat yang digunakan dalam penelitian ini adalah timbangan analitik, 
baskom, sendok, gelas ukur, saringan, kertas $\mathrm{pH}$, pengaduk, kain kasa, dandang, kompor gas, gelas beker, gelas ukur, termometer, toples plastik, talenan dan oven. Sedangkan bahan baku yang digunakan adalah rumput laut kering jenis Kappaphycus alvarezii yang diperoleh dari Kecamatan Tuminting, Kota Manado, Sulawesi Utara. Rumput laut dibawa ke Laboratorium Pengendalian Mutu Hasil Perikanan, Fakultas Perikanan dan Ilmu Kelautan Universitas Sam Ratulangi Manado untuk diproses lebih lanjut.

Proses ekstraksi karaginan dilakukan mengacu pada protokol Harun dkk., (2013) dengan detilnya sebagai berikut:

1. Rumput laut kering ditimbang sebanyak 250 gram;

2. Dicuci dengan air yang mengalir hingga bersih, kemudian direndam dalam $\mathrm{KOH}$ $(0,05 \%, \quad 0,1 \%, 0,15 \%)$ sesuai dengan perlakuan yang diencerkan dalam akuades, dan didiamkan selama 24 jam;

3. Dicuci kembali dengan air yang mengalir hingga diperoleh $\mathrm{pH}$ netral 7;

4. Rumput laut dipotong-potong menjadi kecil $( \pm 1 \mathrm{~cm})$;

5. Rumput laut diekstraksi selama 2 jam dengan perbandingan rumput laut dan air 1 $\mathrm{kg}: 20$ liter dan $1 \mathrm{~kg}: 30$ liter;

6. Setelah proses ekstraksi selesai maka dilakukan penyaringan dengan kain saring dalam keadaan panas untuk mempermudah penyaringan sehingga diperoleh filtrate;

7. Fitrat dicampurkan dengan $\mathrm{KCl}$ sesuai dengan perlakuan, dan didiamkan selama 30 menit. Larutan $\mathrm{KCl}$ digunakan untuk proses pengendapan karaginan;

8. Endapan karaginan dimasukan dalam oven dengan suhu $60-80^{\circ} \mathrm{C}$ sampai kering selama 2 hari (48 jam);

9. Tepung karaginan selanjutnya ditimbang untuk proses analisa.

\section{Perlakuan dan Persiapan Sampel}

Perlakuan yang digunakan dalam penelitian ini, pelarut $\mathrm{KOH}$ dengan konsentrasi $0,05,0,1$ dan $0,15 \%$ sedangkan pelarut $\mathrm{KCl}$ dengan konsentrasi $1,1,15,1,25,1,5,3$ dan 4,5\%, lama pemasakan 2 dan 3 jam, perbandingan air 1:20 L dan 1:30 L. Parameter mutu karaginan yang dianalisa adalah: kekuatan gel, nilai $\mathrm{pH}$, kadar air dan kadar abu. Metode yang digunakan adalah percobaan (eksperimen) dan data dianalisa secara deskripsi. Dengan ulangan dalam penelitian ini sebanyak 2 kali ulangan untuk setiap kombinasi perlakuan.

\section{Prosedur Analisa}

Analisa yang digunakan dalam penelitian ini adalah kekuatan gel dengan Texture Analyzer, Nilai pH (AOAC, 1984), Kadar abu (AOAC, 1995), Kadar air (AOAC, 1995).

\section{HASIL DAN PEMBAHASAN}

Hasil penelitian ektraksi karaginan dari rumput laut merah jenis Kappaphycus alvarezii dengan menggunakan prosedur analisis yaitu kekuatan gel, nilai $\mathrm{pH}$, kadar abu, dan kadar air dapat dilihat pada Tabel 1 .

Tabel 1. Data rata-rata kekuatan gel, kadar abu, kadar air, dan nilai pH karaginan rumput laut merah Kappaphycus alvarezii.

\begin{tabular}{ccccc}
\hline $\begin{array}{c}\text { Kode } \\
\text { Sampel }\end{array}$ & $\begin{array}{c}\text { Kekuatan } \\
\text { Gel g/cm }\end{array}$ & $\begin{array}{c}\text { Nilai } \\
\mathbf{p H}\end{array}$ & $\begin{array}{c}\text { Kadar } \\
\text { Abu (\%) }\end{array}$ & $\begin{array}{c}\text { Kadar } \\
\text { Air (\%) }\end{array}$ \\
\hline A & 114.57 & 7.75 & 29.03 & 19.885 \\
B & 149.80 & 8.10 & 34.50 & 18.47 \\
C & 147.43 & 8.18 & 27.90 & 18.96 \\
D & 133.73 & 8.00 & 24.59 & 22.37 \\
E & 152.03 & 7.40 & 18.63 & 19.28 \\
F & 188.53 & 8.04 & 19.99 & 17.75 \\
\hline
\end{tabular}

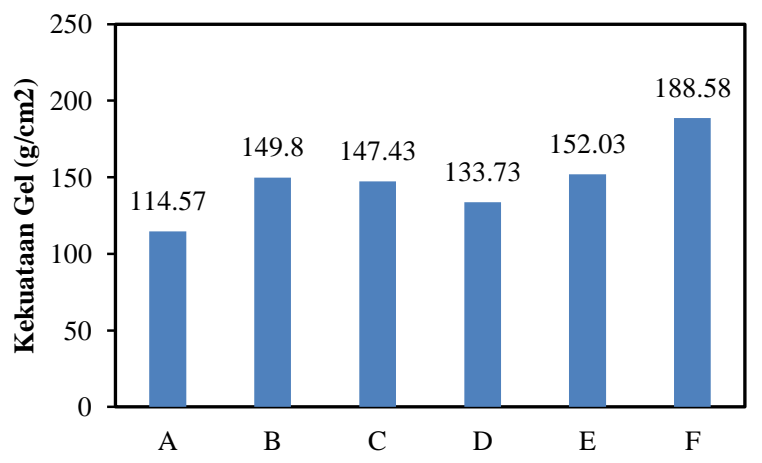

Gambar 1. Histogram pengaruh konsentrasi koh terhadap kekuatan gel pada rumput laut Kappaphycus alvarezii.

Kekuatan gel karaginan yang diperoleh dari hasil penelitian ini berkisar antara 114,57$188,53 \mathrm{~g} / \mathrm{cm}^{2}$. Kekuatan gel tertinggi diperoleh dari perlakuan lama pemasakan 2 jam, perbandingan sampel dan air 20 liter, konsentrasi $\mathrm{KOH} 0,15 \%$, dan $\mathrm{KCL} 1,25 \%$ adalah $188,53 \mathrm{~g} / \mathrm{cm}^{2}(\mathrm{~F})$, sedangkan nilai terendah diperoleh dari perlakuan lama pemasakan $2 \mathrm{jam}$, perbandingan sampel dan air

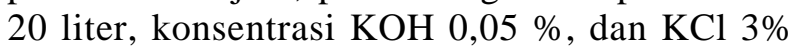
adalah $114,57 \mathrm{~g} / \mathrm{cm}^{2}$ (A). Hasil uji yang dilakukan menunjukkan bahwa perlakuan $\mathrm{F}$ 
mempunyai nilai kekuatan gel tertinggi diikuti berturut-turut oleh sampel E, B, C, D dan A.

\section{Nilai pH}

Dari hasil penelitian ini maka pengukuran $\mathrm{pH}$ Karaginan yang diekstraksi dari Rumput Laut Kappaphycus alvarezii di peroleh $7,40-8,18$. Pada penelitian ini nilai $\mathrm{pH}$ tertinggi terdapat pada perbandingan air dengan Sampel 30 liter, lama pemasakan 3 jam $\mathrm{KOH} 0,1 \%+$ $\mathrm{KCl} 1 \%$ (Sampel C) yaitu 8,18 , sedangkan nilai $\mathrm{pH}$ terendah terdapat pada Perbandingan air dengan Sampel 30 liter, lama pemasakan 3 jam $\mathrm{KOH} 0,15 \%+\mathrm{KCl} 1,15 \%$ yaitu 7,40 (Sampel E). Data sampel yang di dapat pada penelitian ini dimana pada Sampel A dan E pada penelitian ini berkisar antara 7,40 dan 7,75 dimana data ini berada dalam kisaran $\mathrm{pH}$ yang disyaratkan oleh SNI 16-4399-1996 yaitu pH netral. Sedangkan pada Sampel B, C, E dan F berkisar antara $8,00-8,18$ yaitu $\mathrm{pH}$ basa. Gambar 2 memperlihatkan kisaran nilai $\mathrm{pH}$ karaginan rumput laut merah Kappaphycus alvarezii.

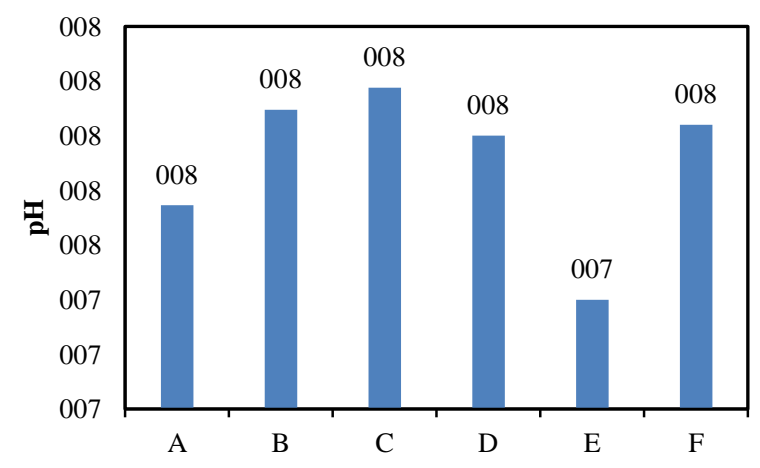

Gambar 2. Histogram pH karaginan rumput laut Kappaphycus alvarezii.

\section{Kadar Abu}

Hasil analisis kadar abu tepung karaginan pada penelitian ini berkisar antara 18,63-34,50 (Gambar 3). Kadar abu tertinggi terdapat pada sampel B yaitu $34,50 \%$. Sedangkan kadar abu terendah terdapat pada sampel E yaitu $18,63 \%$. Hasil ini menunjukkan bahwa kadar abu yang diperoleh memenuhi standar mutu karaginan yang ditetapkan FAO sebesar 15-40\% dan FCC menetapkan maksimum $35 \%$.

Gambar 3 menunjukkan bahwa konsentrasi $\mathrm{KOH}$ memberikan pengaruh terhadap kadar abu yang dihasilkan dalam pembuatan karaginan. Hal ini yaitu kadar abu yang tertinggi terdapat pada sampel $\mathrm{B}$ dengan konsentrasi $\mathrm{KOH} 0,05 \%$, dan rata-ratanya adalah $34,56 \%$. Sedangkan kadar abu yang terkecil pada sampel E dengan konsentrasi $\mathrm{KOH} \quad 0,15 \%$ rata-ratanya adalah $18,63 \%$. Menurut Winarno (1997) tingginya kadar abu karaginan dipengaruhi oleh adanya garam dan mineral lain yang menempel pada rumput laut seperti natrium, kalsium dan literum.

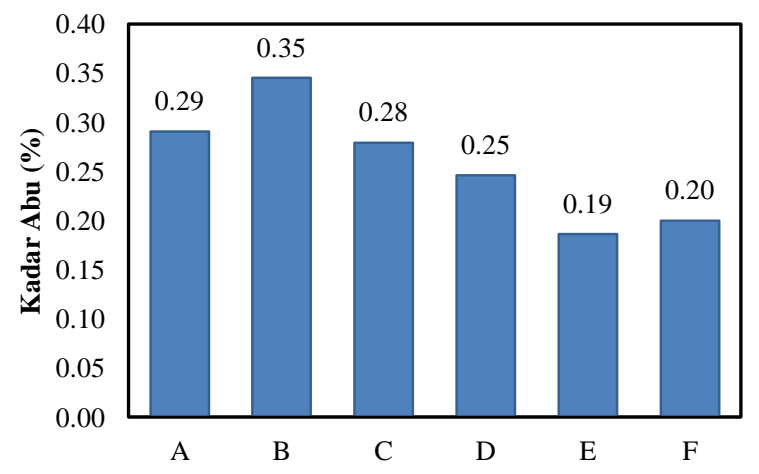

Gambar 3. Histogram kadar abu karaginan rumput laut Kappaphycus alvarezii.

\section{Kadar Air}

Hasil analisis kadar air pada tepung karaginan pada penelitian ini berkisar antara $17,75 \%$ sampai $22.37 \%$ (Gambar 4). Kadar air tertinggi terdapat pada sampel $\mathrm{D}$ dengan konsentrasi $\mathrm{KOH} \quad 0,01 \%$ yaitu $22,37 \%$. Sedangkan kadar air terendah pada sampel $\mathrm{F}$ konsentrasi $\mathrm{KOH} 0,15 \%$ yaitu $17,75 \%$. kadar air menunjukkan tidak ada perbedaan antar perlakuan. Murdinah (2010) melaporkan bahwa kadar air tepung karaginan yang diperoleh dalam penelitiannya berkisar antara 13,45$14,72 \%$. Kadar ini masih cukup tinggi bila dibandingkan dengan standar FAO tepung karaginan yaitu maksimal $12 \%$.

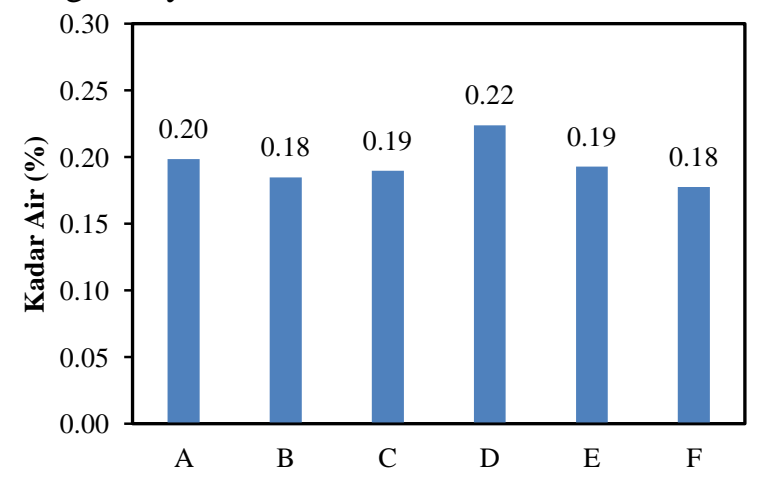

Gambar 4. Histogram kadar air karaginan rumput laut Kappaphycus alvarezii.

Hasil analisis memberikan keterangan bahwa faktor yang mempengaruhi dalam proses ekstraksi ini adalah adanya penambahan 
pengendap menggunakan pengendap $\mathrm{KCl}$. Hal ini disebabkan adanya pengendap mengakibatkan serat-serat karaginan lebih banyak terbentuk dan membentuk gel, sehingga kadar air dalam karaginan menjadi berkurang.

\section{KESIMPULAN}

Berdasarkan data yang telah didapatkan dari penelitian yang telah dilakukan, maka dapat ditarik beberapa kesimpulan sebagai berikut:

1. Kekuatan gel terbaik yaitu $188,53 \mathrm{~g} / \mathrm{cm}^{2}$ terdapat pada perlakuan F (Perbandingan air dengan Sampel 20 liter, lama pemasakan 2 jam $\mathrm{KOH} 0,15 \%+\mathrm{KCl} 1,25 \%$ );

2. Nilai $\mathrm{pH}$ terbaik yaitu mendekati netral $(7,40)$ terdapat pada perlakuan $\mathrm{E}$ (Perbandingan air dengan Sampel 30 liter, lama pemasakan 3 jam $\mathrm{KOH} 0,15 \%+\mathrm{KCL}$ $1,15 \%)$;

3. Kadar abu tepung karaginan pada penelitian ini berkisar antara 18,63-34,50\% menunjukkan bahwa kadar abu yang diperoleh memenuhi standart mutu karaginan yang ditetapkan FAO sebesar 1540\% dan FCC menetapkan maksimum 35\%.

4. Kadar air terbaik yaitu $17,75 \%$ terdapat pada perlakuan $\mathrm{F}$ ((Perbandingan air dengan Sampel 20 liter, lama pemasakan 2 jam $\mathrm{KOH} 0,15 \%+\mathrm{KCl} 1,25 \%)$;

5. Secara keseluruhan dapat disimpulkan bahwa perlakuan terbaik dalam penelitian ini adalah perlakuan $\mathrm{F}$ (Perbandingan air dengan Sampel 20 liter, lama pemasakan 2 jam, $\mathrm{KOH} 0,15 \%+\mathrm{KCl} 1,25 \%)$ karena mempunyai kekuatan gel tertinggi, $\mathrm{pH}$ mendekati netral, kadar abu sesuai standar, dan kadar air terendah pada penelitian ini.

\section{DAFTAR PUSTAKA}

Emma. S,. Tenriulo, A,. Tampangalo, B. R,. 2010. Pelestarian Plasma Nutfa Rumput Laut Kappaphycus alvarezii (Doty) Melalui Industri Kalus dan Embriogenesis secara Invitro. Badan Riset Perikanan Budidaya Air Payau Riset Perikanan Budidaya Kementrian Kelautan dan Perikanan, Sulawesi Selatan.

Harun. M, Roike.I. Montolalu., dan I. Kentut Suwetja. 2013. Karakteristik Fisik Kimia Karaginan Rumput Laut Jenis Kappaphycus alvarezii. Jurnal Media Teknologi Hasil Perikanan Universitas Sam Ratulangi.

Istini, S. dan Suhaimi., 1998. Manfaat dan Pengolahan Rumput Laut. Lembaga Oseanologi Nasional, Jakarta.

Kordi. K. M. G. H,. 2010. Kiat Sukses Budidaya Rumput Laut di Laut dan di Tambak. Penerbit Andi. Yogyakarta.

Murdinah. 2010. Pengaruh bahan pengestrak dan bahan penjendalan terhadap mutu karaginan dari rumput laut Kappaphycus alvarezii. Jakarta

Suwandi, 1992. Isolasi dan Identifikasi Karaginan Dari Rumput Laut Eucheuma cottonii. Lembaga Penelitian Universitas Sumatra Utara, Medan.

Winarno. F. G. 1997. Teknologi Pengolahan Rumput laut. Pustaka Sinar Harapan. Jakarta. Hlm. 112. 